\title{
Identification of bap and icaA genes involved in biofilm formation in coagulase negative staphylococci isolated from feline conjunctiva
}

\author{
Katarzyna Płoneczka-Janeczko • Paweł Lis • \\ Karolina Bierowiec • Krzysztof Rypula • \\ Pawel Chorbiński
}

Received: 17 July 2014 / Accepted: 19 August 2014 / Published online: 2 September 2014

(C) The Author(s) 2014. This article is published with open access at Springerlink.com

\begin{abstract}
Bap and icaA genes are commonly known to be involved in the biofilm formation. The prevalence of bap and icaA genes and biofilm formation was determined in conjunctival isolates of coagulase negative staphylococci (CNS) collected from cats. The study was conducted on 90 archival CNS isolates collected from feline conjunctiva obtained from clinically healthy cats and cats with ocular problems. Biofilm formation was examined using the microtiter plate (MTP) method. The prevalence of icaA and bap genes was determined using polymerase chain reaction (PCR). Genetic profiles of the bap-positive isolates were examined using the modified random amplified polymorphic DNA (RAPD) method. Of the $90 \mathrm{CNS}$ isolates investigated, $58.9 \%$ (53/90) were confirmed to form biofilms on a polystyrene plate after $24 \mathrm{~h}$, and the intensity of the biofilm production varied strongly between positive strains. Among the biofilm-producing isolates, $24.5 \%(13 / 53)$ carried the icaA gene and $3.8 \%$ $(2 / 53)$ carried the bap gene. Among the isolates that did not produce biofilms, the icaA gene and bap gene were detected in $8.1 \%(3 / 37)$ and $2.7 \%(1 / 37)$ of isolates, respectively. This is the first report demonstrating that CNS isolated from feline conjunctiva can potentially be a bap gene reservoir. Preliminary comparison of the genetic profiles of three bappositive isolates collected from cats showed that each of the isolates has a different genetic background with a high similarity with the human strain of $S$. epidermidis.
\end{abstract}

K. Płoneczka-Janeczko $(\bowtie) \cdot$ P. Lis $\cdot \mathrm{K}$. Bierowiec $\cdot$ K. Rypuła $\cdot$ P. Chorbiński

Department of Epizootiology with Clinic for Birds and Exotic Animals, Faculty of Veterinary Medicine, Wrocław University of Environmental and Life Sciences, Plac Grunwaldzki 45, 50-366 Wrocław, Poland

e-mail: ploneczka@poczta.onet.pl
Keywords Conjunctiva Coagulase negative staphylococci · Biofilm $\cdot$ bap $\cdot i c a A \cdot$ Cats

\section{Introduction}

Differentiation between colonization and infection is a problem in the field of medicine because the same microorganisms can be isolated from clinically healthy animals and animals with clinical manifestations of different infections. Consequently, there has been an increase in the number of studies that focus on commensal microflora and detailed analysis of bacteria, in terms of the decision regarding the eventual introduction of antimicrobial therapy. Researchers have focused on whether commensal microorganisms can exhibit specific invasive traits and properties, which will decide their enhanced virulence (Honda et al. 2010; Murphy et al. 2011)

Microbial biofilm formation is commonly accepted as one of the mechanisms of bacterial virulence as well as resistance (Cucarella et al. 2001; Mah and O'Tolle 2001). The first analysis of microbial cell immobilization in the matrix of extracellular polymers acting as an independent functioning ecosystem that is homeostatically regulated, as biofilms are defined, date back to the 1940s (Percival and Knottenbelt 2011). In recent years, research on the development and presence of biofilms has focused on its implications for the treatment and control of isolated bacteria (Palmer and White 1997). Due to the use of new imaging technologies such as episcopic differential interference contrast microscopy combined with epifluorescence (EDIC/EF) and laser scanning confocal microscopy (LSCM), better visualization of biofilm structure has been achieved (Percival and Knottenbelt 2011)

Various extracellular substances, e.g., extracellular polysaccharides and biofilm-associated proteins, enable bacteria 
to form biofilms. Production of these components is dependent on the presence of biofilm-essential genes such as the $i c a$ operon or bap gene (Percival and Knottenbelt 2011). Bap is a relatively recently identified gene that has been described to encode the surface protein involved in biofilm formation (Valle et al. 2012). The prevalence of the bap gene seems to be quite low and ranges between 5 and $10 \%$ in staphylococci isolated from animals with mastitis (Cucarella et al. 2001). In human clinical isolates of Staphylococcus aureus, the presence of bap gene was not shown (Cucarella et al. 2001). Alternatively, approximately $91 \%$ of human clinical isolates of Acinetobacter baumanii, a causative agent of a hospital infection resistant to antimicrobial therapy, were positive for the bap gene (Goh et al. 2013). In bap-positive isolates of Staphylococcus aureus, the described gene was localized within the putative composite transposon inserted in the mobile staphylococcal pathogenicity island SaPIbov2 (Staphylococcal pathogenicity island bovine 2) (Tormo et al. 2005). The ica operon (icaABCD), with the $i c a A$ gene (intercellular adhesion gene) responsible for polysaccharide intercellular adhesin poly- $N$-succinyl $\beta-1-6$ glucosamine (PIAPNSG) formation, plays an independent role in the biofilm composition and intercellular adhesion (Cucarella et al. 2001; Potter et al. 2009). In human medicine, up to $80-90 \%$ of clinical isolates of $S$. epidermidis and even one-third of saprophytic strains have been shown to carry the ica gene (Møretrø et al. 2003). Biofilms are implicated in approximately $80 \%$ of all infections (urinary tract infections, middle-ear infections, dental plaque, gingivitis or wounds infections), which also are caused by CNS that in the past have long been regarded as nonpathogenic (Percival and Knottenbelt 2011; O'Gara and Humphreys 2001). However, some properties of CNS, such as biofilm production, suggest that these bacteria may play a significant role in the pathogenesis of some infections (hospital-acquired infections, central nervous system shunt infections, endocarditis, urinary tract infections and endophthalmitis) (Huebner and Goldmann 1999) CNS, especially Staphylococcus simulans, belong to the resident flora of the feline skin (Scott et al. 2001) The prevalence of CNS isolated from the cat population appears to be related to the clinical status of the animal. In studies carried out on cats in Grenada, CNS have been found in samples obtained from urinary tract infections, pyogenic lesions, and otitis externa cases (Hariharan et al. 2009). In addition, the results of a study among a healthy feral cat population showed a high frequency of Staphylococcus felis and S. simulans isolation. Bacteria from both species were frequently isolated from feline vagina, ears and eyes (Hariharan et al. 2011). Similarly, Cox et al. (1985) have described S. simulans in clinically healthy cats and regarded it to be the most frequently isolated CNS in the examined population (Cox et al. 1985). Moreover, CNS are the predominant bacterial species among the conjunctiva of all companion animal species (Gellat et al. 2013). In clinically normal cats studied by Espinola and Lilenbaum, CNS were detected on the surface of the palpebral conjunctiva, third eyelid, and eyelid margin (Espinola and Lilenbaum 1996). There are no data from veterinary ophthalmology regarding the correlation between some properties of CNS like biofilm production within the conjunctiva and the clinical manifestation of ocular diseases, however, it has been shown that CNS may be implicated in ulcerative keratitis cases in a variety of species, including humans (Lin and Petersen-Jones 2007).

This work presents molecular evidence of icaA and bap genes, which are involved in biofilm production, in conjunctival isolates of CNS in cats and quantification of the biofilm using the microtiter plate (MTP) method in vitro.

\section{Materials and methods}

A total of 90 archival isolates of CNS (bacterial glycerol stocks in $15 \%$ sterile glycerol, stored at $-80{ }^{\circ} \mathrm{C}$ ) collected at the Department of Epizootiology, Faculty of Veterinary Medicine, Wrocław University of Environmental and Life Sciences, were analyzed in this study. In total, 90 isolates of CNS were taken from 90 cats. Thirty-seven CNS isolates were derived from feline conjunctival swabs taken from cats with ocular problems by veterinarians in private veterinary practices. In most cases serous to muco-purulent ocular discharge, oedema and/or hyperemia of conjunctiva were the reasons of examination (described in referrals) and a problem was recognized clinically as conjunctivitis. It is unknown whether the infection was caused by Chlamydophila felis, Mycoplasma felis, or feline herpes virus (no commissions for laboratory diagnostic). Fifty-three CNS isolates were obtained from clinically healthy animals, without ocular problems. Conjunctival swabs were collected with owner's consent during visits (vaccination, anti-worming treatment, other laboratory tests) in the Veterinary Practice at the Department of Epizootiology. Identification of the CNS strains (genus level) was performed in the Veterinary Diagnostic Laboratory "Epi-vet" of the Department of Epizootiology by culturing on the BD Mannitol Salt Agar, observing colony characteristics, Gram staining, hemolytic properties on blood agar and resistance to novobiocin. Additionally detection of enzyme production (coagulase tube test) was performed.

Archival strains of bacteria were directly inoculated on Chapman medium and incubated for $24 \mathrm{~h}$ at $37^{\circ} \mathrm{C}$. The obtained subcultures (singles colonies) were used for the DNA isolation experiment (Genomic Mini AX Bacteria Spin, A\&A Biotechnology, Poland) and the biofilm formation test using the MTP method (Los et al. 2010). The CNS subcultures (single colonies) were suspended in tryptic soy broth (TSB) (Graso, Poland) and cultured for $24 \mathrm{~h}$ at $37^{\circ} \mathrm{C}$. Biofilm formation was examined using MTP procedures in a 96-well plate. After an overnight culture in TSB, the culture 
was diluted 1:100 in TSB, and $200 \mu \mathrm{l}$ of the suspension was added into three wells. The plate was incubated for $24 \mathrm{~h}$ at $37{ }^{\circ} \mathrm{C}$ and then washed two times with $200 \mu$ l of sterile phosphate-buffered saline. Next, the plate was air-dried for $2 \mathrm{~h}$ in an inverted position before it was stained with $200 \mu \mathrm{l}$ of $0.1 \%$ crystal violet for $10 \mathrm{~min}$. Two biofilm measurement procedures described by Jain and Darwish were tested, but in order to standardize the measurements (possible biofilms diversity), the protocol that dissolved the stain first was selected (Darwish and Asfour 2013; Jain and Agarwal 2009). After the next washing (as described above), the stain bound to bacteria was dissolved by adding $250 \mu \mathrm{l}$ of $95 \%$ ethanol, and the absorbance was determined at $570 \mathrm{~nm}$ on an enzyme-linked immunosorbent assay plate reader ( $\mu$ Quant). The positive controls included two strains with the capacity to form a biofilm: Staphylococcus epidermidis PCM 2532 (ATCC 35984) (PAN, Wrocław) and S. simulans ATCC 1362, shared by J. R. Penades. As a negative control, sterile TSB was used as proposed by Darwish and Asfour (2013). The MTP procedure was performed three times, in triplicate for each CNS archival strain.

Biofilm-formation capability was considered positive at a cut-off level 0.324, which was established by the mean for the negative control (culture medium, 0.244) plus two standard deviations (0.04). For the positive biofilm formers, the classification criteria were established as follows:

- weak biofilm formers:

$0.324<\mathrm{A}_{570}<0.648(2 \times$ negative control $)$

- medium-positive biofilm formers:

$0.648<\mathrm{A}_{570}<1.296(4 \times$ negative control $)$

- strong biofilm formers:

$\mathrm{A}_{570}>1.296(4 \times$ negative control $)$

The presence of the two biofilm-related genes, icaA and bap, was determined by duplex polymerase chain reaction (PCR), using the modified methods that has been widely studied (Tormo et al. 2005; Hou et al. 2012). The primer sequences used for amplification of icaA and bap of Staphylococcus spp. were as follows:

icaAF: 5'-TCTCTTGCAGGAGCAATCAA-3' icaAR: 5'-TCAGGCACTAACATCCAGCA-3' bapF: 5'-CCCTATATCGAAGGTGTAGAATTGCAC-3' bapR: 5'-GCTGTTGAAGTTAATACTGTACCTGC-3'

The reaction volume was $25 \mu \mathrm{l}$, containing: $0.5 \mu \mathrm{M}$ icaAF, $0.5 \mu \mathrm{M}$ icaAR, $0.3 \mu \mathrm{M}$ bapF, $0.3 \mu \mathrm{M}$ bapR, $0.3 \mathrm{mM}$ dNTP, $2.5 \mu$ of DreamTaq Green buffer, 1.5 U of DreamTaq DNA polymerase (Thermo Scientific, Lithuania), and $2 \mu \mathrm{l}$ of matrix DNA. Amplification was performed as follows: $95{ }^{\circ} \mathrm{C}$ for $3 \mathrm{~min}$; 40 cycles of $95{ }^{\circ} \mathrm{C}$ for $30 \mathrm{~s}, 52{ }^{\circ} \mathrm{C}$ for $30 \mathrm{~s}$, and $72{ }^{\circ} \mathrm{C}$ for $1 \mathrm{~min}$; and $72{ }^{\circ} \mathrm{C}$ for $5 \mathrm{~min}$. Electrophoresis was performed on $2 \%$ agarose gel with Midori Green (NIPPON Genetics EUROPE GmbH).

The amplified product was purified using a DNA extraction and purification kit (Fermentas International Inc., Canada). Sequencing reactions of randomly selected icaApositive $(n=3)$ and all bap-positive $(n=3)$ PCR products were performed by Genomed (Warsaw, Poland). The sequences were deposited in GenBank (KF972122-KF972127).

The nucleotide sequences of four CNS isolates collected from feline conjunctiva (PJLB-1, PJLB-3, and PJLB-4 for $i c a A$ and PJLB-1, PJLB-2, and PJLB-3 for bap) and sequences obtained from GenBank were aligned by ClustalW software and were analyzed using the Molecular Evolutionary Genetics Analysis (MEGA6) program (Tamura et al. 2004; Tamura et al. 2012). The GenBank database accession numbers of the pathogens used for comparison in this study are as follows:

icaA: gi/111143321/gb/DQ836165.1/Staph. epidermidis strain YT-118

gi/111143324/gb/DQ836166.1/Staph. epidermidis strain YT-82

gi/111143335/gb/DQ836167.1/Staph. epidermidis strain YT-55

gi/111610631/gb/DQ846811.1/Staph. epidermidis strain YT-50

gi/111610633/gb/DQ846812.1/Staph. epidermidis strain YT 169-a

gi/223955852/gb/FJ472951.2/Staph. haemolyticus strain $25-59$

gi/402696806/gb/JX298872.1/Staph. aureus strain KVAFSU-133

bap: gi/63034432/gb/DQ008306.1/Staph. epidermidis gi/406047572/gb/JX403946.1/ Staph. aureus strain KVAFSU-50

gi/2624021112/gb/EU011246.2/Staph. haemolyticus strain Hp-69

gi/444329455/gb/HQ170520.3/Staph. simulans $b v$. staphylolyticus strain NNRL 2628

gi/63034434/gb/DQ008307/ Staph. hyicus

gi/63034428/gb/DQ008304.1/Staphylococcus xylosus

Taking into account that in the field of veterinary medicine the bap gene involved in biofilm formation has been found only in a small proportion of examined bacteria, the genetic relationship between all confirmed bap-positive isolates was established using the modified random amplified polymorphic DNA (RAPD) method described by van Belkum et al., with the primer 1204 (5'-ATGTAAGCTCCTGGGGATTCAC-3') (van Belkum et al. 1993). The PCR volume was $25 \mu \mathrm{l}$, containing $1.6 \mu \mathrm{M} 1204$ primer, $1.25 \mathrm{mM}$ dNTP, $2.5 \mu \mathrm{l}$ of DreamTaq Green buffer, 2 U of DreamTaq DNA polymerase (Thermo Scientific, Lithuania), $1 \mu$ l of matrix DNA, and $18.2 \mu \mathrm{l}$ of milliQ water. The PCR conditions were as follows: 
37 cycles of $95^{\circ} \mathrm{C}$ for $30 \mathrm{~s}, 40{ }^{\circ} \mathrm{C}$ for $30 \mathrm{~s}$, and $72{ }^{\circ} \mathrm{C}$ for $30 \mathrm{~s}$ with ramping of $0.2{ }^{\circ} \mathrm{C} / \mathrm{s}$ in each step. Electrophoresis was performed on $3 \%$ agarose gel with Midori Green (NIPPON Genetics EUROPE GmbH).

A $P$ value $<0.05$ was considered to indicate a statistically significant association. Statistical analysis of the data in selected groups was accomplished using Fischer's test and the Student's t-test.

Ethics Statement. This study was reviewed and approved by the Institutional Animal Care and Use Committee (Local Ethics Commission for Experiments on Animals in Wroclaw, Wroclaw University of Environmental and Life Sciences). Feline conjunctival swabs were taken from cats with ocular problems as well as clinically healthy cats by veterinarians in veterinary practices. The swabs were collected with owner's consent during visits (vaccination, anti-worming treatment, other laboratory tests) with minimized distress.

\section{Results}

Of the 90 conjunctival CNS isolates investigated, $58.9 \%$ (53/ 90) were confirmed to form biofilm on the polystyrene plate after $24 \mathrm{~h}$. The percentage of biofilm-positive strains in cats without ocular problems and in cats with clinical manifestation of eyes disease amounted to $54.7 \%(29 / 53)$ and $64.9 \%$ (24/37), respectively ( $p=0.38$; Fisher's exact test).

In total, the mean absorbance $\left(\mathrm{A}_{570}\right)$ for all examined $\mathrm{CNS}$ strains was measured to be 0.397 ; and for biofilm-positive strains, it was 0.510 . The intensity of the biofilm production varied strongly between positive strains. Of the 53 positive strains examined, $84.9 \%(45 / 53)$ were confirmed to be weak biofilm formers and $13.2 \%(7 / 53)$ were medium biofilm formers. Only $1.8 \%(1 / 53)$ of all positive strains showed a strong capacity to produce biofilm.

The absorbance measurement results $\left(\mathrm{A}_{570}\right)$ for cats with ocular problems and clinically healthy cats with unchanged conjunctiva are given in Table 1 . The cats with ocular problems showed higher percentage of medium $(13,51 \%, 5 / 37)$ and strong $(2,7 \%, 1 / 37)$ biofilm-forming CNS isolates than healthy animals $(3,77 \%, 2 / 53$ and $0 \%, 0 / 53)$; however, the obtained results were not statistically significant $(p=0.06$, Fisher's exact test). Although the mean absorbance for the biofilm-positive strains only was greater $(0.560 \pm 0.264)$ in cats with ocular problems than in healthy ones $(0.468 \pm$ $0.135)$ ( $p=0.10$; Student's t-test) and the mean absorbance calculated for the strong and medium biofilm formers in cats with ocular problems was greater $(0.933 \pm 0.274)$ than in healthy ones $(0.847 \pm 0.205)(p=0.09$, Student's t-test), the differences were not statistically significant. In addition, the ability to form a strong biofilm was confirmed for ill animals only.
Among the biofilm-producing isolates ( $n=53), 13$ (24.5\%) were carriers of the $i c a A$ gene and $2(3.8 \%)$ were carriers of the bap gene. Among the isolates that did not produce a biofilm $(n=$ $37)$, the icaA gene and bap gene were detected in $3(8.1 \%)$ and 1 $(2.7 \%)$ CNS strains, respectively. There was a remarkable difference between the prevalence of the icaA gene ( $p=0.01$ *, Fisher's test) in cats with unchanged conjunctiva and in cats with ocular problems. However, there was not a statistically significant difference $(p=1)$ in the prevalence of the bap gene between these two populations. Table 1 presents a detailed distribution of the icaA and bap genes.

Figures 1 and 2 show the independent phylogenetic analysis of the icaA and bap genes confirmed in the CNS strains. Sequencing was performed for four selected CNS strains (No $24,40,57,60$ ), and all double-positive isolates (icaA and bap) were included. Taking into account the $i c a A$ gene, comparison of the results obtained by the direct sequencing of three independently collected isolates showed that the sequences of two of them (PJLB-1 and PJLB-4) were identical to S. epidermidis YT-50 and YT-169.a. PJLB-3 was different from these two strains and was highly similar to S. epidermidis strains YT-55, YT-82, and YT-118, and Staphylococcus haemolyticus strain 25-59. Sequence analysis of the bap gene showed that strain PJLB-2 was identical to S. epidermidis gi/63034432, described by Tormo et al. (2005), and that PJLB-1 and PJLB-3 share high similarity with the isolates described above.

Figure 3 presents a preliminary comparison of the genetic profiles of the three bap-positive isolates of CNS collected from cats, based on the modified RAPD method described by van Belkum et al. (van Belkum et al. 1993). The band pattern obtained in the analysis showed that each of the isolates has a different genetic background and that one of them is highly similar to the human strain of $S$. epidermidis ATCC PCM (PAN, Wrocław).

\section{Discussion}

The results of this study provide clinical significance of CNS and their properties in the fields of human medicine as well as veterinary medicine and food hygiene. CNS have attracted increasing interest as they have been isolated from mastitis in dairy animals, they are potential zoonotic pathogens, and they have the capability to produce enterotoxins in food (El-Jakee et al. 2013; Davis et al. 2013; Podkowik et al. 2013). Another factor that should be taken into account is that CNS may produce biofilms. In the natural environment, this fact may change the potential of the described microorganisms to cause an infection. Biofilm-related genes such as icaA or bap are involved in cell aggregation and accumulation of the components of the biofilm. The observed differences between the prevalence of the $i c a$ gene have given rise to discrimination 
Table 1 The biofilm production (MTP method, Absorbance $\mathrm{A}_{570}$ ) and presence of icaA and bap genes in coagulase negative staphylococci (CNS) isolated from feline conjunctiva. Numbers from 1 to 37: cats with ocular problems; numbers from 38 to 90 : clinically healthy animals, with unchanged conjunctiva

\begin{tabular}{|c|c|c|c|c|c|c|c|}
\hline No of sample & Mean absorbance $\mathrm{A}_{570}$ & negative $\mathrm{BF} *$ & Weak BF* & Medium BF* & Strong BF* & $i c a A$ & bap \\
\hline \multicolumn{8}{|c|}{ Cats with ocular problems } \\
\hline 1. & 0,757 & & & + & & neg & neg \\
\hline 2. & 0,803 & & & + & & neg & neg \\
\hline 3. & 0,478 & & + & & & neg & neg \\
\hline 4. & 0,787 & & & + & & neg & neg \\
\hline 5. & 0,449 & & + & & & neg & neg \\
\hline 6. & 0,417 & & + & & & neg & neg \\
\hline 7. & 0,293 & + & & & & neg & neg \\
\hline 8. & 0,393 & & + & & & neg & neg \\
\hline 9. & 0,423 & & + & & & neg & neg \\
\hline 10. & 0,302 & + & & & & neg & neg \\
\hline 11. & 0,224 & + & & & & neg & neg \\
\hline 12. & 0,238 & + & & & & neg & neg \\
\hline 13. & 0,166 & + & & & & neg & neg \\
\hline 14. & 0,691 & & & + & & neg & neg \\
\hline 15. & 1,329 & & & & + & neg & neg \\
\hline 16. & 1,236 & & & + & & neg & neg \\
\hline 17. & 0,513 & & + & & & neg & neg \\
\hline 18. & 0,478 & & + & & & neg & neg \\
\hline 19. & 0,448 & & + & & & neg & neg \\
\hline 20. & 0,337 & & + & & & neg & neg \\
\hline 21. & 0,326 & & + & & & neg & neg \\
\hline 22. & 0,419 & & + & & & neg & neg \\
\hline 23. & 0,252 & + & & & & neg & neg \\
\hline 24. & 0,422 & & + & & & POS & POS \\
\hline 25. & 0,192 & + & & & & neg & neg \\
\hline 26. & 0,518 & & + & & & neg & neg \\
\hline 27. & 0,236 & + & & & & neg & neg \\
\hline 28. & 0,330 & & + & & & neg & neg \\
\hline 29. & 0,553 & & + & & & neg & neg \\
\hline 30. & 0,646 & & + & & & neg & neg \\
\hline 31. & 0,131 & + & & & & neg & neg \\
\hline 32. & 0,277 & + & & & & neg & neg \\
\hline 33. & 0,216 & + & & & & neg & neg \\
\hline 34. & 0,201 & + & & & & neg & neg \\
\hline 35. & 0,354 & & + & & & neg & neg \\
\hline 36. & 0,218 & + & & & & neg & neg \\
\hline 37. & 0,354 & & + & & & POS & neg \\
\hline
\end{tabular}

Healthy cats

$\begin{array}{ll}38 . & 0,578 \\ 39 . & 0,328 \\ 40 . & 0,551 \\ 41 . & 0,112 \\ 42 . & 0,204 \\ 43 . & 0,369 \\ 44 . & 0,271\end{array}$

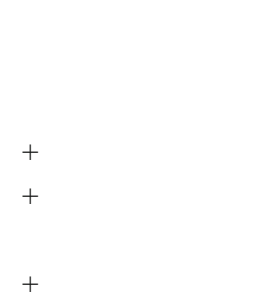

$\begin{array}{ll}\text { neg } & \text { neg } \\ \text { neg } & \text { neg } \\ \text { neg } & \text { POS } \\ \text { neg } & \text { neg } \\ \text { neg } & \text { neg } \\ \text { POS } & \text { neg } \\ \text { neg } & \text { neg }\end{array}$


Table 1 (continued)

\begin{tabular}{|c|c|c|c|c|c|c|c|}
\hline No of sample & Mean absorbance $\mathrm{A}_{570}$ & negative $\mathrm{BF} *$ & Weak BF* & Medium BF* & Strong BF* & $i c a A$ & bap \\
\hline 45. & 0,238 & + & & & & neg & neg \\
\hline 46. & 0,469 & & + & & & neg & neg \\
\hline 47. & 0,349 & & + & & & POS & neg \\
\hline 48. & 0,361 & & + & & & neg & neg \\
\hline 49. & 0,485 & & + & & & neg & neg \\
\hline 50. & 0,418 & & + & & & neg & neg \\
\hline 51. & 0,407 & & + & & & neg & neg \\
\hline 52. & 0,508 & & + & & & POS & neg \\
\hline 53. & 0,486 & & + & & & neg & neg \\
\hline 54. & 0,431 & & + & & & POS & neg \\
\hline 55. & 0,546 & & + & & & neg & neg \\
\hline 56. & 0,323 & + & & & & POS & neg \\
\hline 57. & 0,287 & + & & & & POS & POS \\
\hline 58. & 0,533 & & + & & & POS & neg \\
\hline 59. & 0,461 & & + & & & neg & neg \\
\hline 60. & 0,518 & & + & & & POS & neg \\
\hline 61. & 0,407 & & + & & & POS & neg \\
\hline 62. & 0,129 & + & & & & neg & neg \\
\hline 63. & 0,136 & + & & & & neg & neg \\
\hline 64. & 0,240 & + & & & & neg & neg \\
\hline 65. & 0,321 & + & & & & neg & neg \\
\hline 66. & 0,130 & + & & & & neg & neg \\
\hline 67. & 0,135 & + & & & & neg & neg \\
\hline 68. & 0,420 & & + & & & neg & neg \\
\hline 69. & 0,290 & + & & & & neg & neg \\
\hline 70. & 0,352 & & + & & & POS & neg \\
\hline 71. & 0,562 & & + & & & POS & neg \\
\hline 72. & 0,519 & & + & & & neg & neg \\
\hline 73. & 0,275 & + & & & & neg & neg \\
\hline 74. & 0,290 & + & & & & neg & neg \\
\hline 75. & 0,384 & & + & & & neg & neg \\
\hline 76. & 0,259 & + & & & & neg & neg \\
\hline 77. & 0,280 & + & & & & neg & neg \\
\hline 78. & 0,294 & + & & & & neg & neg \\
\hline 79. & 0,399 & & + & & & neg & neg \\
\hline 80. & 0,297 & + & & & & neg & neg \\
\hline 81. & 0,334 & & + & & & neg & neg \\
\hline 82. & 0,317 & + & & & & neg & neg \\
\hline 83. & 0,992 & & & + & & POS & neg \\
\hline 84. & 0,225 & + & & & & neg & neg \\
\hline 85. & 0,242 & + & & & & POS & neg \\
\hline 86. & 0,245 & + & & & & neg & neg \\
\hline 87. & 0,356 & & + & & & neg & neg \\
\hline 88. & 0,273 & + & & & & neg & neg \\
\hline 89. & 0,361 & & + & & & POS & neg \\
\hline 90. & 0,702 & & & + & & neg & neg \\
\hline
\end{tabular}

* $B F$ biofilm formers

Entries in bold indicates the sequenced isolates (icaA and bap) 


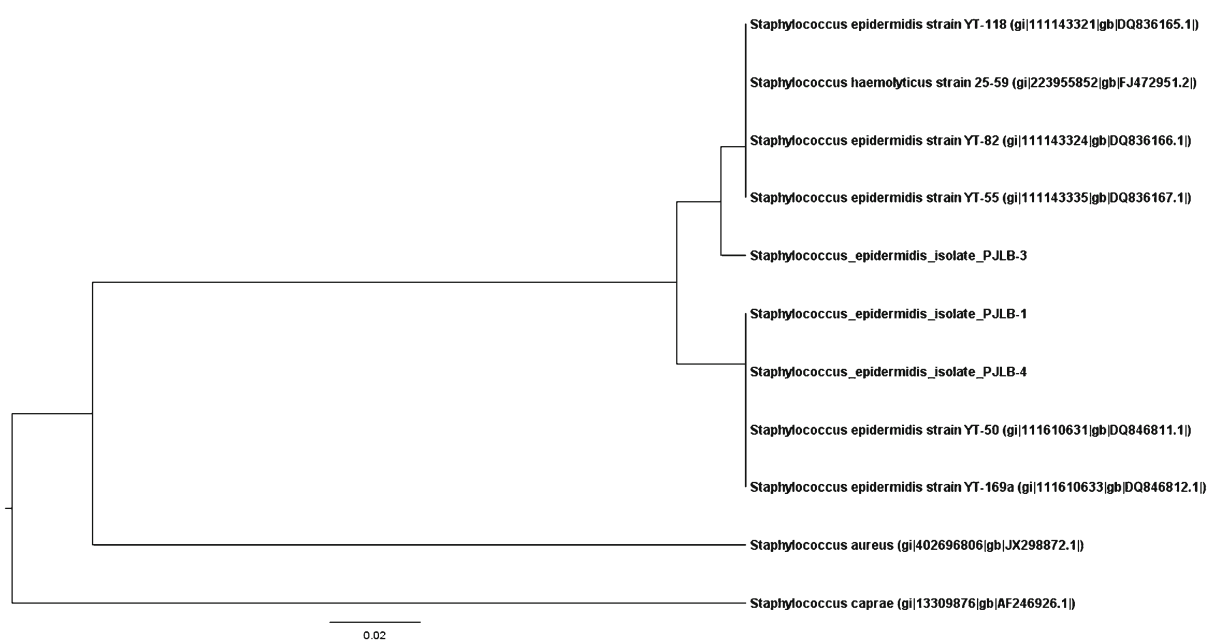

Fig. 1 Dendrogram representing the $i c a A$ gene diversity in conjunctival CNS isolates collected from cats in comparison to other sequences obtained from GenBank. Analyzed strains were recognized as S. epidermidis. The similarity tree was inferred using the unweighted pair group method with the arithmetic mean (UPGMA). The optimal tree with the sum of branch length $=0.30669999$ is shown. The tree is drawn to scale, with branch lengths in the same units as those of the evolutionary distances used to infer the phylogenetic tree. The evolutionary distances

between virulent and avirulent strains (Percival and Knottenbelt 2011).

Biofilm formation is well-documented in staphylococci. It has been studied in humans with ocular infection. Murugan et al. have isolated multi-drug resistant Staphylococcus spp. from clinical cases of conjunctivitis and have confirmed that approximately $90 \%$ of them can produce biofilms (Murugan et al. 2010). Biofilms are also implicated in the pathogenesis of acute conjunctivitis related to punctal plugs (Yokoi et al. were computed using the maximum composite likelihood method and are in the units of the number of base substitutions per site (Tamura et al. 2004). The analysis involved ten nucleotide sequences. Codon positions included were $1 \mathrm{st}+2 \mathrm{nd}+3 \mathrm{rd}+$ Noncoding. All ambiguous positions were removed for each sequence pair. There were a total of 189 positions in the final dataset. Evolutionary analyses were conducted using MEGA6 software (Tamura et al. 2012)

2000). In a study by Hou et al. (2012), $28.1 \%$ of investigated CNS bacterial strains were found to be positive using the MTP test and $40.63 \%$ were classified as icaA gene carriers. The authors of the mentioned study have suggested that the observed in vitro biofilm production may correspond to the biofilm formation within the eye. In addition, Suzuki et al. have described a high prevalence of biofilm-forming $S$. epidermidis with the icaA gene (60\%) collected from the conjunctival sac in humans (Suzuki et al. 2005).

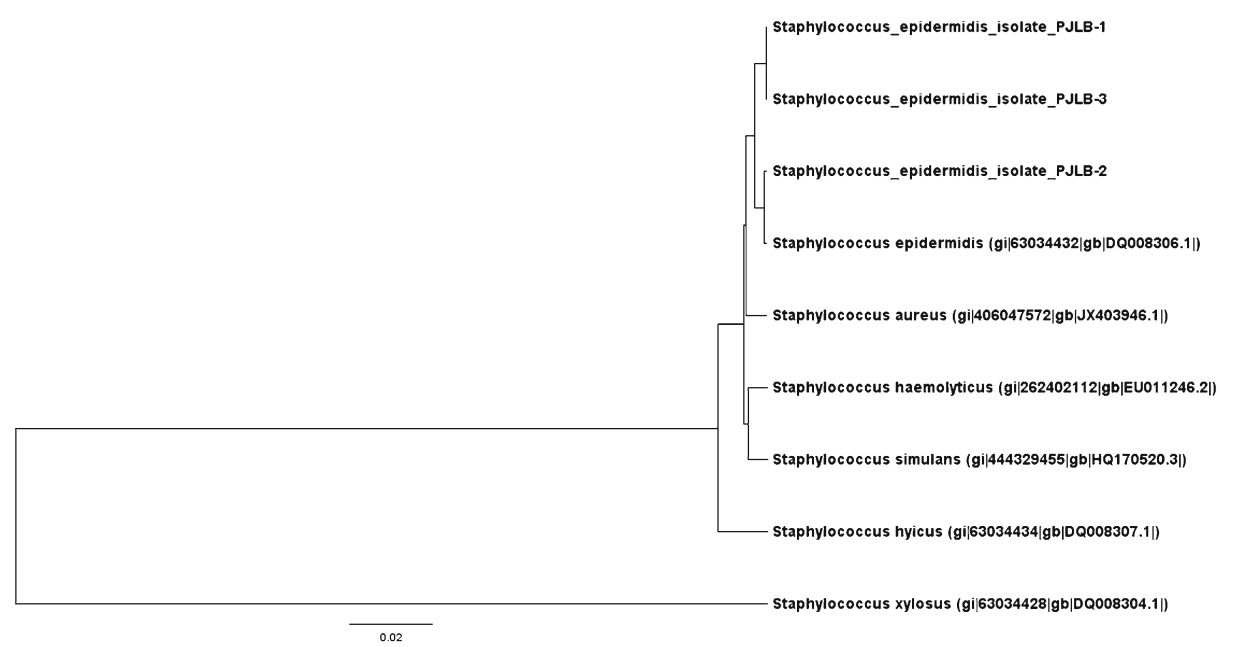

Fig. 2 Dendrogram representing the bap gene diversity in conjunctival CNS isolates collected from cats in comparison to other sequences obtained from GenBank. Analyzed strains were recognized as $S$. epidermidis. The similarity tree was inferred using the UPGMA method. The optimal tree with the sum of branch length $=0.38994523$ is shown. The tree is drawn to scale, with branch lengths in the same units as those of the evolutionary distances used to infer the phylogenetic tree.
The evolutionary distances were computed using the maximum composite likelihood method and are in the units of the number of base substitutions per site (Tamura et al. 2004). The analysis involved nine nucleotide sequences. Codon positions included were $1 \mathrm{st}+2 \mathrm{nd}+3 \mathrm{rd}+$ Noncoding. All ambiguous positions were removed for each sequence pair. There were a total of 900 positions in the final dataset. Evolutionary analyses were conducted using MEGA6 software (Tamura et al. 2012) 


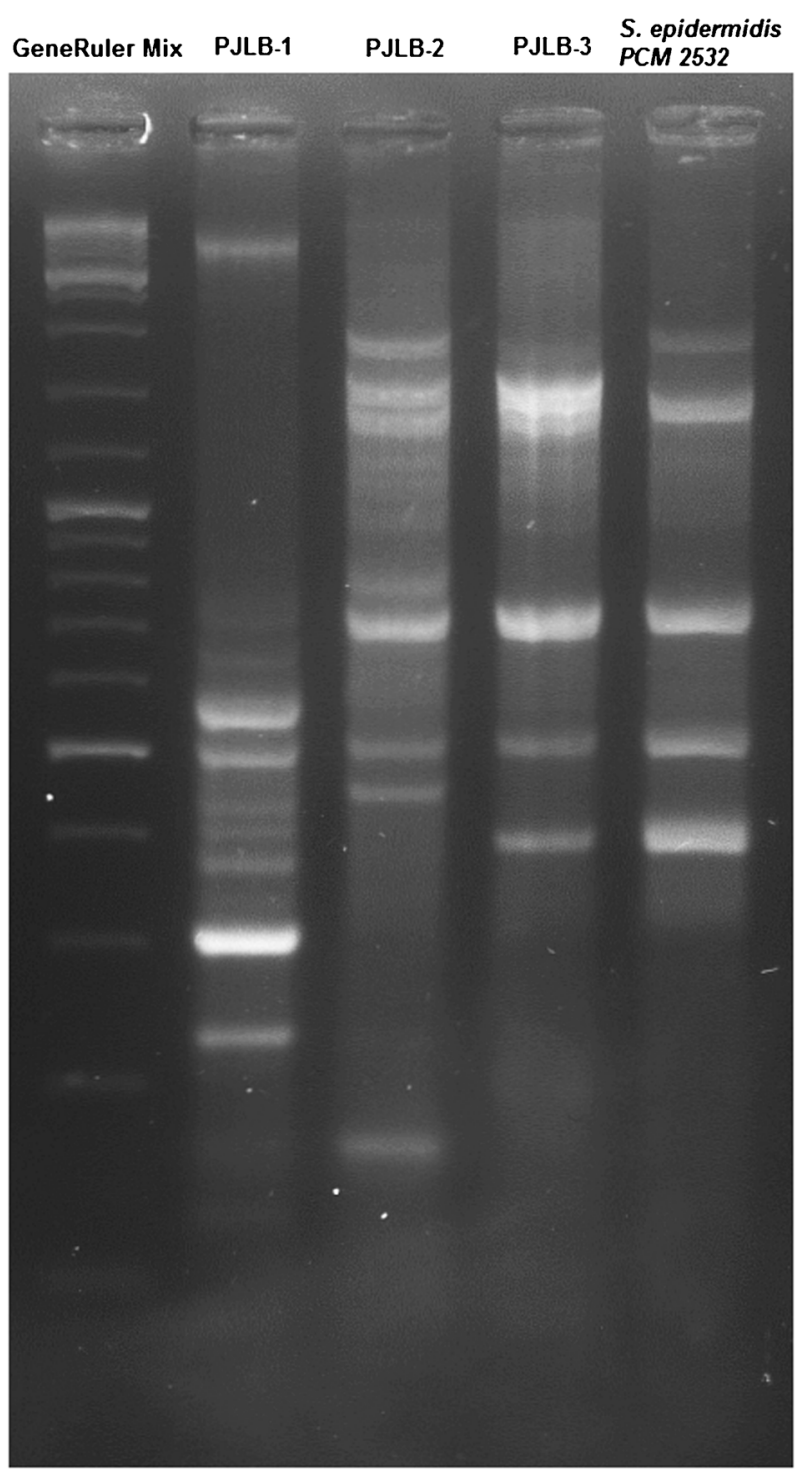

Fig. 3 Genetic profiles of the three bap-positive isolates of CNS collected from cats and a control strain (PCM 2532) based on the modified RAPD method described by van Belkum et al. (1993)

In our research, we measured in vitro biofilm formation in the setting of veterinary ophthalmology. It is dependent on several genetic determinants, regulators and environmental conditions (Percival and Knottenbelt 2011). Even though the surface of the feline conjunctiva is a difficult place to form biofilms due to tear flow, antibacterial components of the tear film, and cat's behavior, the ability to produce biofilms in vitro was confirmed in a high percentage of examined CNS isolates. The prevalence of biofilm-forming CNS isolates was higher than the prevalence of the two examined genes icaA and bap. Under various environmental conditions, there are different genetic requirements for biofilm production (Pratt and Kolter 1999). In our research, the biofilm formation properties after $24 \mathrm{~h}$ were determined using the MTP test and the presence of chosen genes involved in biofilm formation was examined in molecular studies. The biofilm formation assay in our study was performed only at one set of conditions and far from the natural, in vivo conditions. On the other hand, the creation of experimental biofilm-forming conditions mimicking feline conjunctiva, with lacrimal secretions and inhibitory compounds and especially with behavioral factors (scratching, rubbing) exceed the practical possibilities of this research.

The biofilm formation ability among CNS isolates appears to be unrelated to the clinical stage of the conjunctiva; these results in cats contrast with the results obtained in human medicine (Hou et al. 2012; Murugan et al. 2010). However, it should be noted that the feline conjunctivitis is usually caused by primary infection with viruses (FHV-1), Mycoplasma spp., or Chlamydophila spp. The ability to rule out the abovementioned pathogens limits our conclusions and in the light of obtained results, CNS may be considered only as pathogens that may complicate a primary infection. Acquaintance with the full virological and bacteriological status of feline conjunctiva would allow the determination of whether CNS (and its biofilm formation) may be responsible for ocular problems.

Taking into account that several other genes may be involved in biofilm production, systematic analysis of these genes in conjunctival CNS in cats is needed to determine a correlation with these properties. Since the surface of conjunctiva, by nature, is not optimal place to form biofilm, further research should investigate the adhesion properties of the strains. It has been reported that the ica genes are present in CNS from different sources and hosts, whereas the original research describing bap suggest that this gene was uniquely present in animals (Li et al. 2012; Szweda et al. 2012). Vautor et al. did not identify the bap gene among 262 isolates of $S$. aureus collected from various animal species but cats or dogs were not included in the study (Vautor et al. 2008). In addition, Szweda et al. (2012) examined $S$. aureus strains $(n=$ 132 ) isolated from cows with mastitis, and they found that all strains were also bap-negative (Szweda et al. 2012).

In conclusion, this study indicated that the prevalence of biofilm-producing strains among conjunctival isolates of CNS is relatively high, but prevalence alone should not be overinterpreted as critical for the pathogenesis of ocular problems (especially conjunctivitis) associated with CNS in cats. Further studies focusing on the expression of the detected genes of biofilms and prevalence of other genetic determinants is needed, as in the presented study a strain carrying both bap and icaA genes was isolated, which did not exhibit biofilm formation, possibly due to the variations of expression of the mentioned genes (bap) (Thormo et al. 2007). Examined genes that may be involved in the clinical state of conjunctiva in cats and expanding the spectrum of research regarding the genes that may be responsible for these properties may determine the prospective course of veterinary diagnostic 
investigation in the field of ophthalmology. It would also be interesting to perform a functional study and determine whether it is possible to insert the two examined genes (icaA and bap) using a plasmid as a vector into biofilm-negative isolates of CNS and estimate whether phenotypic changes (in this case, biofilm formation) follows. It has been shown in $S$. aureus that the presence of a plasmid containing the bap gene influences the biofilm formation ability (Cucarella et al. 2001).

Another factor that should be taken into account is whether the eventual transmission of biofilm-forming strains occurs between humans and animals or direct, horizontal transfer of the analyzed genes may exist between the strains (Tormo et al. 2005). Sequencing of the bap and icaA genes isolated from cats and comparison with sequences from Gene Bank should show that the same isolates of $S$. epidermidis may circulate between cats and humans. Moreover, genetic analysis of bappositive strains with the use of the RAPD method confirmed this hypothesis for one of the tested isolates.

To the best of our knowledge, this is the first report demonstrating the presence of the bap gene in conjunctival isolates of CNS collected from cats as well as in S. epidermidis isolated from cats. For this reason, this should be considered a risk factor for horizontal transmission of the bap gene in the environment.

Acknowledgments The author would like to thank especially Professor Jose R. Penades from the Spanish National Research Council for his cooperation and sharing of the reference strain for this research. This work was supported by the Statutory research of Ministry of Sciences and Higher Education MWet/725/2013/S

Ethical Standards This study was reviewed and approved by the Institutional Animal Care and Use Committee (Local Ethics Commission for Experiments on Animals in Wroclaw, Wroclaw University of Environmental and Life Sciences).

Conflict of Interests The authors declare that there is no conflict of interest

Open Access This article is distributed under the terms of the Creative Commons Attribution License which permits any use, distribution, and reproduction in any medium, provided the original author(s) and the source are credited.

\section{References}

Cox HU, Hoskins JD, Newman SS et al (1985) Distribution of staphylococcal species on clinically healthy cats. Am J Vet Res 46:18241828

Cucarella C, Solano C, Valle J et al (2001) Bap, a Staphylococcus aureus surface protein involved in biofilm formation. J Bacteriol 183:28882896

Darwish SF, Asfour HA (2013) Investigation of biofilm forming ability in Staphylococci causing bovine mastitis using phenotypic and genotypic assays. The Scientific World Journal. Article ID 378492. doi: $10.1155 / 2013 / 378492$
Davis MF, Cain CL, Brazil AM et al (2013) Two coagulase-negative staphylococci emerging as potential zoonotic pathogens: wolves in sheep's clothing? Front Microbiol 4:123. doi:10.3389/fmicb.2013. 00123

El-Jakee JK, Aref NE, Gomaa A et al (2013) Emerging of coagulase negative staphylococci as a cause of mastitis in dairy animals: an environmental hazard. Int J Vet Sci Med 1:74-78

Espinola MB, Lilenbaum W (1996) Prevalence of bacteria in the conjunctival sac and on the eyelid margin of clinically normal cats. J Small Anim Pract 37:364-366

Gellat KN, Gilger BC, Kern TJ (2013) Veterinary ophtalmology: two volume set, vol 5. Wiley, New York

Goh HM, Beatson SA, Totsika M et al (2013) Molecular analysis of the Acinetobacter baumanii biofilm-associated protein. Appl Environ Microbiol 79:6535-6543. doi:10.1128/AEM.01402-13

Hariharan H, Brathweite-Sylvester E, Matthew V (2009) Clinical isolates of bacteria from domestic cats in Granada, and their antimicrobial susceptibility. West Indian Vet J 9:14-16

Hariharan H, Matthew V, Vountain J et al (2011) Aerobic bacteria from mucous membranes, ear canals, and skin wounds of feral cats in Grenada, and the antimicrobial susceptibility of major isolates. Comp Immunol Microbiol Infect Dis 34:129-134

Honda H, Krauss M, Coopersmith C et al (2010) Staphylococcus aureus nasal colonization and subsequent infection in intensive care unit patients: does methicillin resistance matter? Infect Control Hosp Epidemiol 31:584-591. doi:10.1086/652530

Hou W, Sun X, Wang Z et al (2012) Biofilm-forming capacity of Staphylococcus epidermidis, Staphylococcus aureus and Pseudomonas areuginosa from ocular infection. Invest Ophtalmol Vis Sci 53:5624-5631

Huebner J, Goldmann DA (1999) Coagulase-negative staphylococci: Role as pathogenes. Annu Rev Med 50:223-236

Jain A, Agarwal A (2009) Biofilm production, a marker of pathogenic potential of colonizing and commensal staphylococci. J Microbiol Methods 76:88-92. doi:10.1016/j.mimet.2008.09.017

Li L, Yang H, Liu D et al (2012) Analysis of biofilm formation and associated genes detection in Staphylococcus isolates from bovine mastitis. Int J Appl Res Vet Med 10:62-68

Lin CT, Petersen-Jones SM (2007) Antibiotic susceptibility of bacterial isolates from corneal ulcers of dogs in Taiwan. J Small Anim Pract 48:271-274

Los R, Sawicki R, Juda M, Stankevic M, Rybojad P, Sawicki M, Malm A, Ginalska G (2010) A comparative analysis of phenotypic and genotypic methods for the determination of the biofilm-forming abilities of Staphylococcus epidermidis. FEMS Microbiol Lett 310:97-103. doi:10.1111/j.1574-6968.2010.02050.x

Mah TF, O'Tolle GA (2001) Mechanisms of biofilm resistance to antimicrobial agents. Trends Microbiol 9:34-39

Møretrø T, Hermansen L, Holck AL et al (2003) Biofilm formation and the presence of the intercellular adhesion locus ica among Staphylococci from food and food processing environments. Appl Environ Microbiol 69:5648-5655

Murphy E, Spencer S, Young D et al (2011) MRSA colonisation and subsequent risk of infection despite effective eradication in orthopaedic elective surgery. J Bone Joint Surg (Br) 93:548-551. doi:10. 1302/0301-620X.93B4.24969

Murugan K, Usha M, Malathi P et al (2010) Biofilm forming multi drug resistant Staphylococcus spp. among patients with conjunctivitis. Pol J Microbiol 59:233-239

O'Gara JP, Humphreys H (2001) Staphylococcus epidermidis biofilms: importance and implications. J Med Microbiol 50: 582-587

Palmer RJ Jr, White DC (1997) Developmental biology of biofilms: implications for treatment and control. Trends Microbiol 5:435440

Percival SL, Knottenbelt DC (2011) Cochrane CA. Biofilms and veterinary medicine. Springer, Berlin 
Podkowik M, Park JY, Seo KS et al (2013) Enterotoxygenic potential of coagulase-negative staphylococci. Int J Food Microbiol 163:34-40. doi:10.1016/j.ijfoodmicro.2013.02.005

Potter A, Ceotto H, Giambiagi-deMarval M et al (2009) The gene bap, involved in biofilm production, is present in Staphylococcus spp. strains from nosocomial infection. J Microbiol 47:319-326. doi:10. 1007/s12275-009-0008-y

Pratt LA, Kolter L (1999) Genetic analyses of bacterial biofilm formation. Curr Opin Microbiol 2:598-603

Scott DW, Miller WH, Griffin CE (2001) Muller and Kirk's small animal dermatology, vol 6. Saunders Company, Philadelphia

Suzuki T, Kawamura Y, Uno T et al (2005) Prevalence of Staphylococcus epidermidis strains with biofilm-forming ability in isolates from conjunctiva and facial skin. Am J Ophtalmol 140:844 850

Szweda P, Schiellman M, Milewski S et al (2012) Biofilm production and presence of ica and bap genes in Staphylococcus aureus strains isolated from cows with mastitis in the eastern Poland. Pol J Microbiol 61:65-69

Tamura K, Nei M, Kumar S (2004) Prospects for inferring very large phylogenies by using the neighbor-joining method. Proc Natl Acad Sci U S A 101:11030-11035
Tamura K, Stecher G, Peterson D et al (2012) MEGA6: molecular evolutionary genetics analysis version 6.0. Mol Biol Evol 30: 2725-2729. doi:10.1093/molbev/mst197

Thormo MA, Úbeda C, Marti M et al (2007) Phase-variable expression of the biofilm-associated protein (Bap) in Staphylococcus aureus. Microbiology 153:1702-1710. doi:10.1099/mic.0.2006/005744-0

Tormo MA, Knecht E, Götz F et al (2005) Bap-dependent biofilm formation by pathogenic species of Staphylococcus: evidence of horizontal gene transfer? Microbiology 151:2465-2475

Valle J, Latasa C, Gil C et al (2012) Bap, a biofilm matrix protein of Staphylococcus aureus prevents cellular internalization through binding to GP96 host receptor. PLoS Pathog. doi:10.1371/journal. ppat. 1002843

van Belkum A, Bax R, Peerbooms P et al (1993) Comparison of phage typing and DNA fingerprinting by polymerase chain reaction for discrimination of methicillin-resistant Staphylococcu aureus strains. J Clin Microbiol 31:798-803

Vautor E, Abadie E, Pont A et al (2008) Evaluation of the presence of the bap gene in Staphylococcus aureus isolates recovered from humans and animal species. Vet Microbiol 127:407-411

Yokoi N, Okada K, Suquita J et al (2000) Acute conjunctivitis associated with biofilm formation on a punctal plug. Jpn J Ophtalmol 44:559-560 